\title{
A Comparative Evaluation of Different Treatment Regimens in Endotoxemic Buffalo Calves-A Physio-Pathological Perspective
}

\author{
Irtiza Nabi, Digvijay Singh, N. K. Sood
}

Department of Veterinary Physiology and Biochemistry, C. O. V. S, Guru Angad Dev Veterinary \& Animal Sciences University, Ludhiana, India

Correspondence to: Digvijay Singh, digvijay231@rediffmail.com

Keywords: Blood, Buffalo Calves, Dextran-40, Endotoxemia, Flunixin Meglumine, Hypertonic Saline, Physiology and Pathology

Received: February 19, $2019 \quad$ Accepted: April 25, $2019 \quad$ Published: April 28, 2019

Copyright () 2019 by authors and Scientific Research Publishing Inc.

This work is licensed under the Creative Commons Attribution International License (CC BY 4.0).

http://creativecommons.org/licenses/by/4.0/

\section{(c) (1) Open Access}

\section{ABSTRACT}

Fifteen apparently healthy male buffalo calves aged between 6 months to one year with body weight range of $70-140 \mathrm{Kg}$ divided into 3 groups of 5 buffalo calves each were used in the present investigation. Endotoxic shock was produced by IV infusion of Escherichia coli endotoxin @ $5 \mu \mathrm{g} / \mathrm{kg}$ BW/ $\mathrm{hr}$ for 3 hours followed by administration of three different treatment regimens comprising of intravenous infusion of hypertonic saline solution(HSS) @ $4 \mathrm{ml} / \mathrm{Kg}$ bw, flunixin meglumine @ $1.1 \mathrm{mg} / \mathrm{Kg}$ bw and blood @ $20 \mathrm{ml} / \mathrm{Kg}$ bw to group-I, HSS, Dextran-40 and Flunixin meglumine to group-II and HSS, Dextran-40, whole blood and Flunixin meglumine to group-III with the objectives to study the major physio-pathological changes during induced endotoxemia in buffalo calves and to compare the effects of different treatment options to find out the best treatment option out of the three combinations. All the animals were further observed up to day 2 or death whichever was earlier. Endotoxin infusion to all the animals caused symptoms of restlessness, respiratory distress, snoring, diarrhoea, profuse salivation along with the significant hypoproteinemia, hypoalbuminemia, hypoglobulinemia, hypokalemia and hypocalcemia. The treatment with HSS, flunixin meglumine and blood infused as one time infusion to these endotoxemic buffalo calves not only alleviated the above mentioned symptoms but also significantly raised the circulating albumin level at $5.5 \mathrm{hrs}$ and day 2 and Fibrinogen level at day 2 of observation. A significant hypocalcaemia was observed at 4.5 hours along with an increase in Alkaline Phosphatase at 3.5, 4.5 and 6.5 hrs. All the endotoxemic buffalo calves which died were subjected to post mortem and histopathological studies. Epicardial and endocardial haemorrhages, haemorrhages on intestinal mucosa, congestion, haemorrhages, emphysema and 


\begin{abstract}
fibrinous thrombi in microvasculature of lungs were salient histopathological findings. On comparison with observations of the other treatment regimens tried, it was found that the IV infusion of the combination of HSS, Flunixin meglumine, Dextran-40 and blood was found to be the most effective leading to full recovery of 3 out of 5 buffalo calves of group-III where as only 1 out of 5 animals recovered in group-II. None of the group-I animals recovered and all of these succumbed to shock after day- 2 .
\end{abstract}

\title{
1. INTRODUCTION
}

Septic or endotoxic shock is an acute circulatory failure occurring in the presence of severe infection and represents an imbalance between the body's oxygen demands and supply. It is principally of the distributive type, although cardiogenic and hypovolemic components may also be involved [1]. Endotoxin is an integral component of the outer membrane of gram-negative bacteria and the effects of exposure of host cells to it include the uncontrolled release of cytokines and eicosanoids, kinins and other short, medium and long-term reactants that upset the balance between proinflammatory and anti-inflammatory pathways, causing hypotension, disseminated intravascular coagulation, abortion and death [2]. Endotoxemia is a life threatening inflammatory condition, which can lead to shock, multiple organ failure, suppression of immune system and wound-healing processes [3].

Treatment of endotoxemia is difficult because of the numerous mediators involved. There are three possible approaches in treating endotoxemia. The interaction of endotoxin with target cells can be blocked by inducing tolerance, decreasing plasma endotoxin concentrations, or interfering with endotoxin binding [4]. NSAIDS inhibit the production of eicosanoids and TXA-2. Among NSAIDS, Flunixin meglumine is the most effective and is anti-endotoxic at doses much lower than those required for analgesia. Endotoxemia also leads to protein loss and reduced colloidal oncotic pressure. According to [5], there are five therapeutic approaches in the treatment of endotoxemia, including prevention of the synthesis, release or action of inflammatory mediators, prevention of endotoxin induced cellular activation and general supportive care with intravenous (I/V) fluids or colloids and ionotropic agents.

The present investigation was planned with the objectives to study the major physio-pathological changes during induced endotoxemia in buffalo calves and to compare the effects of different treatment options to find out the best treatment option out of the three combinations. These studies could also be extrapolated and be useful for finding suitable therapeutic regimens applicable in other species of animals and man.

\section{MATERIAL AND METHODS}

Fifteen apparently healthy 6 months to one year-old male buffalo calves with body weight range of 70 - $140 \mathrm{Kg}$ were used in the present investigation. These calves were kept under the good managemental conditions as are practiced at the dairy farm, COVS, GADVASU, Ludhiana. All the animals were de-wormed and vaccinated against Haemorrhaegic Septicemia well before the start of experiment.

The Endotoxin ${ }^{1}$ was reconstituted by dissolving it in normal saline solution $(0.9 \% \mathrm{NaCl})$ to make a stock solution of $1 \mathrm{mg} / \mathrm{ml}$. Endotoxin concentration of $5 \mu \mathrm{g} / \mathrm{ml}$ was prepared by dissolving $1 \mathrm{ml}$ of stock solution in $199 \mathrm{ml}$ of normal saline to make a total volume $200 \mathrm{ml}$. The endotoxin was then infused intravenously through jugular vein @ $5 \mu \mathrm{g} / \mathrm{kg} \mathrm{BW} / \mathrm{hr}$ for 3 hours, followed immediately by a rapid infusion of hypertonic saline solution(HSS) @ 4 ml/Kg body weight, Flunixin Meglumine @ $1.1 \mathrm{mg} / \mathrm{Kg}$ body weight \& blood@20 ml/Kg Body weight as one time infusion. The animals were casted in right lateral recumbency on operation table. Before endotoxin infusion, an area over jugular furrow was shaved and disinfected with savlon. The local anesthetic Lignocaine (2\%)@ 90 - $120 \mathrm{ml}$ was injected subcutaneously and intra-muscularly before catheterization of the jugular vein and the carotid artery. The blood samples from

${ }^{1}$ Escherichia coli endotoxin Lyophilized (Phenol extracted) 0111:B4 lipopolysacharide, SIGMA Chemicals U.S.A. 
jugular vein of the endotoxemic buffalo calves were collected in heparin immediately before and after 1.5, $2.5,3.5,4.5,5.5,6.5 \mathrm{hrs}$ of the start of endotoxin infusion, followed by samples at $24 \mathrm{hr}$ of last sample of day 1 , up to $2^{\text {nd }}$ day. The following physiological constituents like the plasma Total Protein, acute phase proteins like Albumin, Fibrinogen, Globulin, Alkaline phosphatase, Creatinine, Glucose, Sodium, Potassium, Calcium and Phosphorus were estimated by Dry stat clinical dry chemistry analyser ${ }^{2}$. Plasma Fibrinogen was estimated using a portable refractometer by comparing the protein in non-heated plasma and that in the respective sample heated to $56^{\circ}$ to $58^{\circ}$ Celsius for 3 minutes [6]. The data so generated was pooled \& analysed with CRD Anova [7]. All the values obtained were compared with the normal pre-infusion values within the group. The trends of the present investigation were compared with other treatment combinations i.e., group-II consisting of HSS, Dextran-40 and Flunixin meglumine and group-III consisting of HSS, Dextran-40, whole blood and Flunixin meglumine to find out the most suitable treatment regimen. All those animals who died consequent to endotoxemia were subjected to the post mortem examination for gross lesions and the tissues were collected in $10 \%$ NBF (Neutral Buffered Saline) for studying the histo pathological changes.

\section{RESULTS AND DISCUSSION}

The results of the physiological profiles estimated during present investigation in group-1 are presented in Table 1 and Figures 1-5. The physiological trends and the pathological lesions of this group have been compared with those in group-II and III which have been published previously by the authors to assess the best treatment regimen. Clinical signs observed due to endotoxemia consisted of restlessness, respiratory distress, forceful abdominal respiration, diarrhoea and profuse salivation. None of the endotoxemic buffalo calves out of five animals of group-I survived beyond the $2^{\text {nd }}$ day.

The normal mean pre-infusion total protein was found to be $6.74 \pm 0.34 \mathrm{~g} / \mathrm{dl}$, which is close to $6.82 \pm$ $0.24 \mathrm{~g} / \mathrm{dl}$ reported by [8], $6.40 \pm 0.19 \mathrm{~g} / \mathrm{dl}$ [9] but lower than $7.54 \pm 0.25 \mathrm{~g} / \mathrm{dl}$ [10]. In the present study, however, a significant $(\mathrm{P}<0.05)$ hypoproteinemia was observed from 1.5 to $3.5 \mathrm{hr}$ after the endotoxin infusion (Table 1) The hypoproteinemia as observed in present investigation (Figure 1) was perhaps due to congestion and lower nephron nephrosis in kidneys observed in present investigation which might have resulted in more albumin excretion through kidney while mild sinusoidal congestion and hepatocellular necrosis in liver may have caused decreased protein synthesis leading to significant hypoproteinemia and hypoalbuminemia.

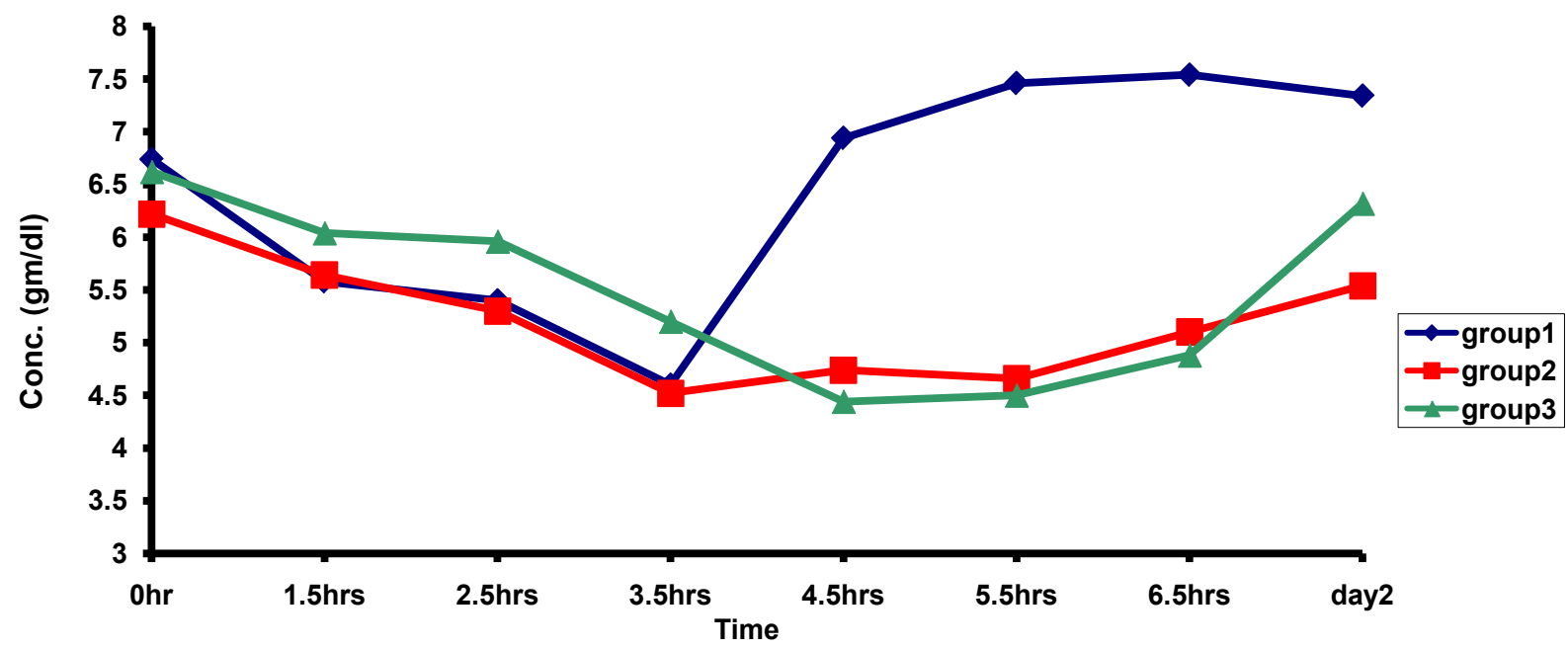

Figure 1. Mean plasma Total protein (gm/dl) at different stages of endotoxic shock and after various treatment combinations.

${ }^{2}$ Dry stat clinical dry chemistry analyser, Johnson \& Johnson, U.S.A. 


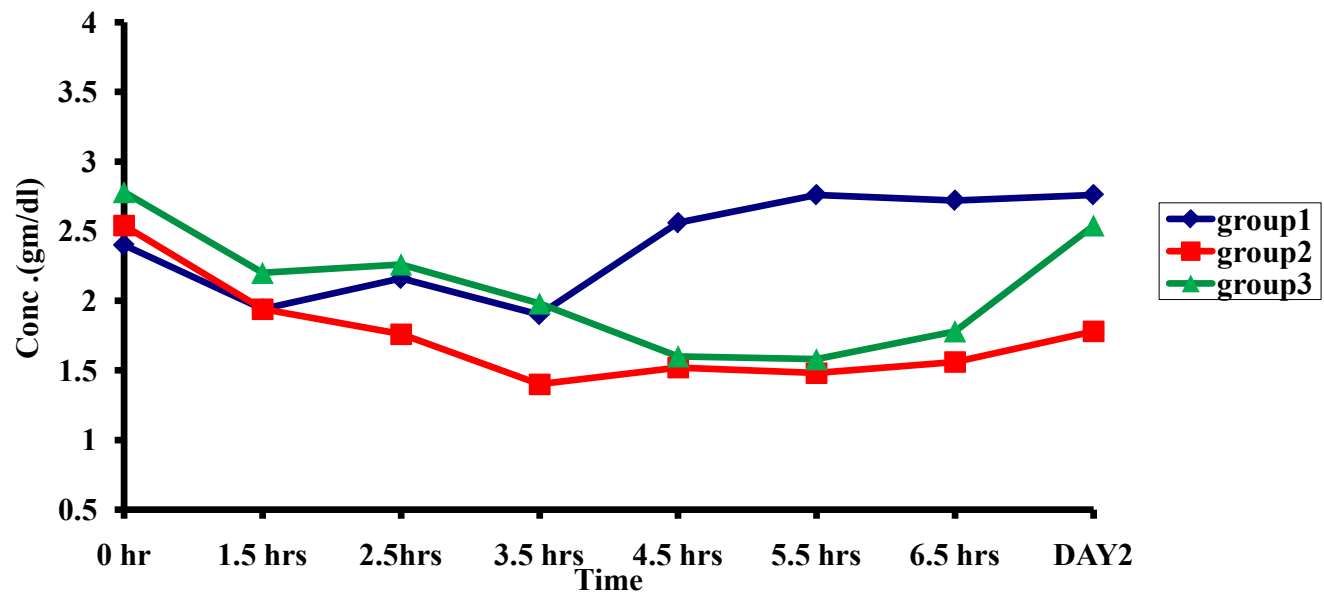

Figure 2. Mean plasma albumin (gm/dl) at different stages of endotoxic shock and after various treatment combinations.

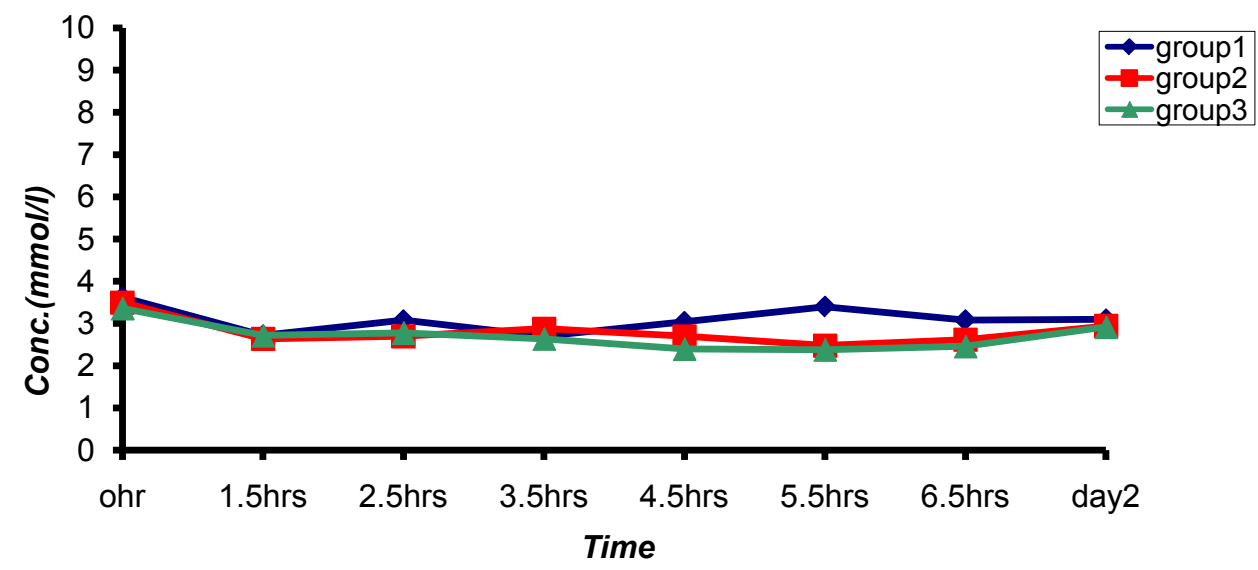

Figure 3. Mean plasma potassium (mmol/l) at different stages of endotoxic shock and after treatment combinations.

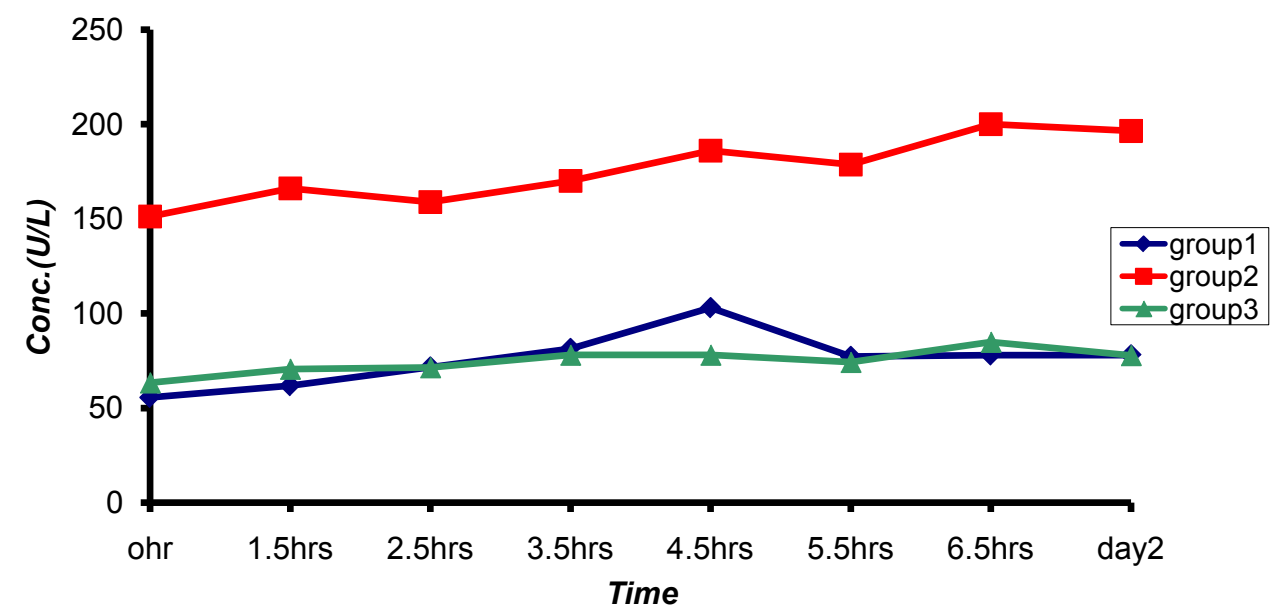

Figure 4. Mean plasma calcium (mg/dl) at different stages of endotoxic shock and after various treatment combinations. 


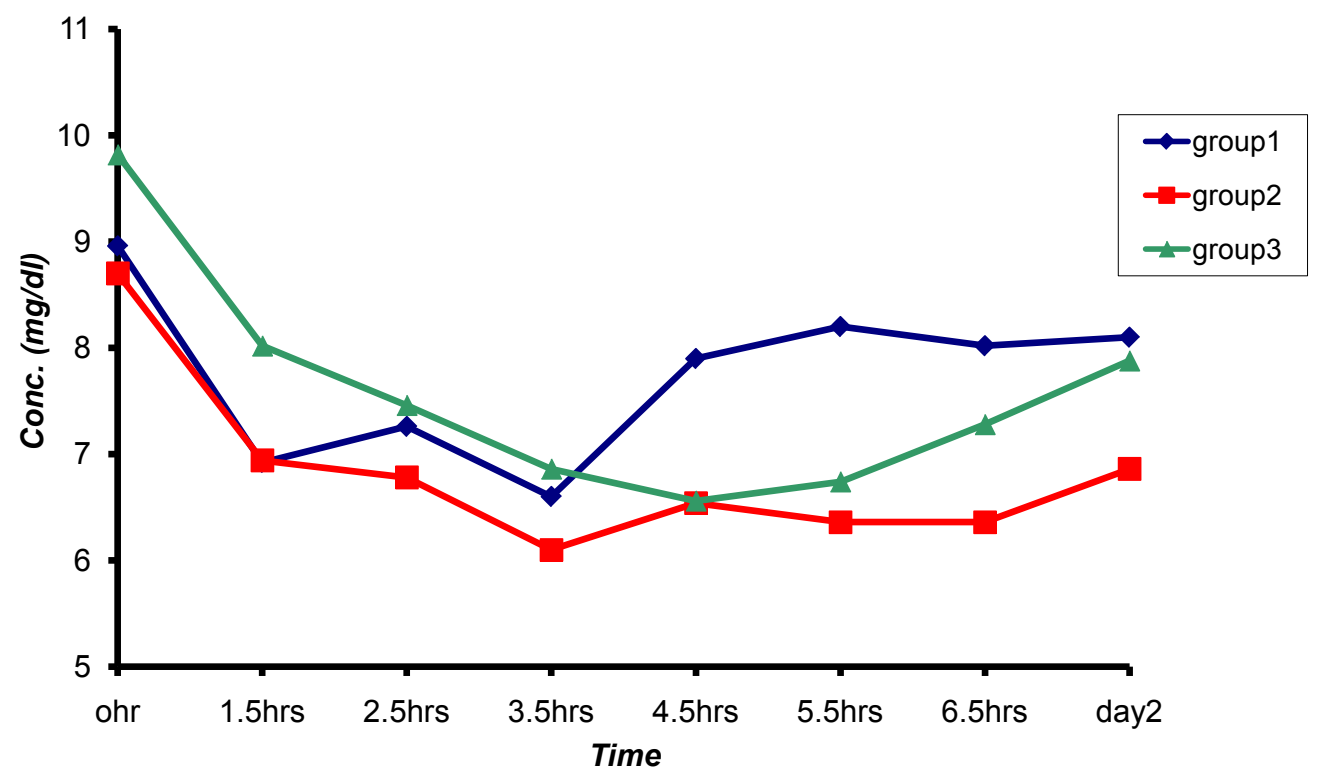

Figure 5. Mean plasma Alkaline phosphatase (U/L) at different stages of endotoxic shock and after various treatment combination.

Table 1. Physiological parameters at different stages of endotoxic shock and after treatment with HSS, Flunixin meglumine and Blood.

\begin{tabular}{|c|c|c|c|c|c|c|c|c|}
\hline \multirow[t]{2}{*}{ Group } & \multicolumn{4}{|c|}{ Endotoxic shock } & \multicolumn{4}{|c|}{ After treatment } \\
\hline & $0 \mathrm{~h}$ & $1.5 \mathrm{~h}$ & $2.5 \mathrm{~h}$ & $3.5 \mathrm{~h}$ & $4.5 \mathrm{~h}$ & $5.5 \mathrm{~h}$ & $6.5 \mathrm{~h}$ & Day 2 \\
\hline \multirow[t]{2}{*}{ Total protein $(\mathrm{g} / \mathrm{dl})$} & 6.74 & $5.58^{*}$ & $5.40^{*}$ & $4.60^{*}$ & 6.94 & 7.46 & 7.54 & 7.34 \\
\hline & \pm 0.34 & \pm 0.50 & \pm 0.51 & \pm 0.38 & \pm 0.15 & \pm 0.07 & \pm 0.11 & \pm 0.05 \\
\hline \multirow{2}{*}{ Albumin (g/dl) } & 2.40 & $1.94^{*}$ & 2.16 & $1.90^{*}$ & 2.56 & $2.76^{*}$ & 2.72 & $2.76^{*}$ \\
\hline & \pm 0.05 & \pm 0.18 & \pm 0.09 & \pm 0.21 & \pm 0.05 & \pm 0.04 & \pm 0.08 & \pm 0.07 \\
\hline \multirow{2}{*}{ Fibrinogen (g/dl) } & 0.20 & 0.36 & 0.32 & 0.44 & 0.52 & 0.48 & 0.80 & 0.92 \\
\hline & \pm 0.00 & \pm 0.04 & \pm 0.08 & \pm 0.12 & \pm 0.08 & \pm 0.14 & \pm 0.46 & $\pm 0.42^{*}$ \\
\hline \multirow{2}{*}{ Globulins (g/dl) } & 4.14 & 3.28 & 2.92 & 2.26 & 3.86 & 4.22 & 4.02 & 3.66 \\
\hline & \pm 0.32 & \pm 0.29 & $\pm 0.58^{*}$ & $\pm 0.35^{\star}$ & \pm 0.05 & \pm 0.14 & \pm 0.55 & \pm 0.47 \\
\hline \multirow{2}{*}{ Potassium (mmol/l) } & 3.62 & 2.72 & 3.08 & 2.70 & 3.04 & 3.4 & 3.08 & 3.1 \\
\hline & \pm 0.44 & $\pm 0.27^{*}$ & \pm 0.21 & $\pm 0.19^{*}$ & \pm 0.06 & \pm 0.14 & \pm 0.16 & \pm 0.14 \\
\hline \multirow{2}{*}{ Calcium (mg/dl) } & 8.96 & 6.92 & 7.26 & 6.60 & 7.90 & 8.20 & 8.02 & 8.10 \\
\hline & \pm 0.29 & $\pm 0.49^{*}$ & $\pm 0.46^{*}$ & $\pm 0.59^{*}$ & $\pm 0.08^{*}$ & \pm 0.07 & \pm 0.14 & \pm 0.11 \\
\hline Alkaline & 55.6 & 61.8 & 71.6 & 81.4 & 103.0 & 77.2 & 78.0 & 78 \\
\hline Phosphatase (U/l) & \pm 4.42 & \pm 10.56 & \pm 7.78 & $\pm 10.88^{*}$ & $\pm 12.26^{*}$ & \pm 3.22 & $\pm 2.12^{*}$ & \pm 2.45 \\
\hline \multirow{2}{*}{ Sodium (mmol/l) } & 135.60 & 134.2 & 134.6 & 128 & 126.2 & 135 & 135 & 133.8 \\
\hline & \pm 1.6 & \pm 4.29 & \pm 3.19 & \pm 6.27 & \pm 3.02 & \pm 6.33 & \pm 7.96 & \pm 7.96 \\
\hline \multirow{2}{*}{ Phosphorus (mg/dl) } & 5.32 & 4.80 & 4.60 & 5.54 & 5.18 & 4.74 & 4.52 & 4.52 \\
\hline & \pm 0.42 & \pm 0.34 & \pm 0.37 & \pm .01 & \pm 0.05 & \pm 0.22 & \pm 0.36 & \pm 0.36 \\
\hline
\end{tabular}

No. of animals in group $=5,{ }^{\star}$ Significant at $5 \%$ level. 
A non-significant hypoproteinemia was continued even after treatment with HSS, flunixin meglumine and blood at 4.5, 5.5 and $6.5 \mathrm{hr}$ up to day 2 of the observation. In fact HSS acutely increases the plasma osmolarity and draws intracellular and interstitial water into the vascular space the protein content of which probably compensates hypoproteinemia. There was plasma volume expansion of $3 \mathrm{ml}$ for every 1 $\mathrm{ml}$ of hypertonic saline infused [11]. Administration of hypertonic saline leads to re-entry of extravascular fluids into the vascular compartment to produce a more rapid response and marked haemodynamic effects than conventional use of isotonic solutions [12]. However the non- significant $(\mathrm{P}<0.05)$ hyperproteinemia found after treatment i.e., at 4.5, 5.5 and $6.5 \mathrm{hr}$. is in contrast to significant hypoproteinemia after treatment observed in other two groups which can be attributed to the rapid plasma volume expansion and redistribution of cardiac output towards splanchnic region, following hypertonic saline solution infusion [13].

The pre-infusion plasma albumin was found to be $2.40 \pm 0.05 \mathrm{~g} / \mathrm{dl}$, which is similar to $2.70 \pm 0.12 \mathrm{~g} / \mathrm{dl}$ reported by [14], but lower than $3.29 \pm 0.13 \mathrm{~g} / \mathrm{dl}$ as reported by [15] and $3.20 \pm 0.19 \mathrm{~g} / \mathrm{dl}$ [16]. A significant $(\mathrm{P}<0.05)$ hypo-albuminemia was observed throughout endotoxin infusion upto $3.5 \mathrm{hrs}$ (Table 1). Hypoalbuminemia was alleviated after treatment and a significant increase was observed at $5.5 \mathrm{hrs}$. and day 2 (Figure 2) which may be due to the albumin in the transfused blood.

In a previous study, [9] also observed significant $(\mathrm{P}<0.05)$ hypoalbuminemia in endotoxin infused buffalo calves. The fall in albumin can be attributed to loss of blood and plasma in tissues, besides diarrhoea [15], the common manifestations in endotoxic shock. The hypo-albuminemia observed in other two groups as well during endotoxin infusion, in turn, may contribute to hypoproteinemia which persisted even after treatment in group-II and III unlike group-I.

The pre-infusion mean plasma fibrinogen recorded was $0.20 \pm 0.00 \mathrm{~g} / \mathrm{dl}$, which is lower than 0.30 to $0.8 \mathrm{gm} / \mathrm{dl}$ [6] and 0.35 to $0.60 \mathrm{~g} / \mathrm{dl} \mathrm{[16]} \mathrm{and} \mathrm{it} \mathrm{increased} \mathrm{significantly} \mathrm{only} \mathrm{on} \mathrm{day} 2$ of the observation (Table 1) which may be due to the fact that endotoxin accelerates fibrinogen synthesis rate [17]. A similar significant increase was observed in group-II at 6.5 hours and day-2 while there was non-significant increasing pattern was observed in group-III [18].

The normal or pre-infusion mean plasma globulins was found to be $4.14 \pm 0.32 \mathrm{~g} / \mathrm{dl}$ (Table 1), which is close to $3.90 \pm 0.39 \mathrm{~g} / \mathrm{dl}$ [14] but higher than $3.24 \pm 0.24 \mathrm{~g} / \mathrm{dl}$ as reported by [15], $2.34 \pm 0.25 \mathrm{~g} / \mathrm{dl}$ [16] and $2.79 \pm 0.13 \mathrm{~g} / \mathrm{dl}$. In the present study, endotoxemic buffalo calves showed significant fall $(\mathrm{P}<0.05)$ in plasma globulins at 2.5 and 3.5 hrs. during endotoxin infusion which was similar to the pattern observed in group-II and III that persisted significantly post treatment as well [13]. After treatment no significant fall in globulins was observed throughout the observation period.

The pre-infusion mean plasma potassium ranged between $3.62 \pm 0.44 \mathrm{mmol} / \mathrm{l}$ (Table 1 ), which is close to $3.60 \pm 0.2 \mathrm{mmol} / \mathrm{l}[20]$ but higher than $2.28 \pm 0.18 \mathrm{mmol} / \mathrm{l}[10]$. A significant $(\mathrm{P}<0.05)$ hypokalemia was observed at 1.5 and $3.5 \mathrm{hrs}$ of the endotoxin infusion. A non-significant hypokalemia was observed after treatment till the end of observation period in group-I where as an overall significant hypokalemia was observed in group II and group III at 1.5, 2.5, 3.5, 4.5, 5.5 and 6.5 hours. The fall in potassium level may be an attempt by the body to sequester potassium as a part of the mechanism, whereby endotoxins promote the release of endogenous pyrogens from leucocytes, and moreover, experiments have shown this process is inhibited by this element.

Decrease in potassium level could also be attributed to release of histamine during endotoxic shock, which increases the capillary permeability and can regulate the secretion of adrenaline and nor-adrenaline together which cause the reduction in potassium level [21]. Hypokalemia after treatment can rather be attributed to rapid volume expansion following HSS infusion. Decrease in plasma levels of sodium and potassium may furthermore be attributed to the greatly diminished active transport of sodium and potassium through the cell membranes. As a result, sodium and chloride accumulate in the cell and the potassium is lost from the cell [21].

The pre-infusion mean plasma calcium observed was $8.96 \pm 0.29 \mathrm{mg} / \mathrm{dl}$ (Table 1 ) which is within the physiological range of $8.7-11.4 \mathrm{mg} / \mathrm{dl}$ as reported [15] and lower than $9.7-12.4 \mathrm{mg} / \mathrm{dl}$ in cattle serum [22]. In the present study, a significant $(\mathrm{P}<0.05)$ hypocalcaemia was observed in group-I throughout the 
endotoxin infusion and even afterwards at $4.5 \mathrm{hrs}$. as also reported previously [23] while hypocalcemia was significant throughout the period of observation till day 2 in group-II and III. The normal mean plasma phosphorus observed was $5.32 \pm 0.42 \mathrm{mg} / \mathrm{dl}$ (Table 1), which is close to physiological value of $5.6-6.5$ $\mathrm{mg} / \mathrm{dl}$ in cattle serum [22]. The plasma phosphorus did not show any significant variation during and after the intravenous infusion of endotoxin and the treatment given thereafter. A similar trend was witnessed in group-II and III as well.

The pre-infusion mean plasma Alkaline phosphatase observed was $55.60 \pm 04.42 \mathrm{U} / 1$ (Table 1) which is lower than $173 \pm 40 \mathrm{U} / \mathrm{l}$ as reported [24]. In the present study, a significant $(\mathrm{P}<0.05)$ rise in plasma alkaline phosphatase was recorded in group-I at 3.5, 4.5 and $6.5 \mathrm{hrs}$. of the observation period which may be due to the fact that alkaline phosphatase enzyme normally represents a pooled heterogenous group derived from various organs like liver, kidney, bone and placenta. The damage to these organs result in to the shift of this enzyme from intracellular compartment to the extracellular compartment i.e., blood plasma [25].

Endotoxin induced injury to the various tissues and organs may be causing increase in alkaline phosphatase levels. In group-II and III, a non-significant rise in alkaline phosphatase though out the period of observation showed very less extent of damage to various organs.

The normal mean plasma sodium observed was $135.60 \pm 1.60 \mathrm{mmol} / \mathrm{l}$, which is close to $136.6 \pm 5.51$ $\mathrm{mmol} / \mathrm{l}$ [16], $134.48 \pm 4.07 \mathrm{mmol} / \mathrm{l}$ [10] and $133.40 \pm 3.19 \mathrm{mmol} / \mathrm{l}$ [26]. A generalized non-significant change in sodium was noticed throughout the period of experiment in group-I which was similar to that observed in group-II and III (Table 1). Similar unappreciable plasma sodium changes were reported in endotoxemic cow [20] and buffalo calves [14]. In the present investigation, the mean sodium level at the end of the observation period was almost equal to pre-infusion level. Absence of any significant increase in plasma sodium even after infusion of HSS is advantageous as it does not cause hypernatremia thus making the infusion of HSS very safe [14].

Pathological lesions: All the endotoxemic buffalo calves died in group-I during observation period were subjected to necropsy examination in order to study the pathological changes where as in group-II, one animal survived beyond period of observation and recovered fully as 4 out of 5 animals died on day 3 4 while in group-III, only 2 animals died on day-3 - 4 and 3 animals survived and recovered fully.

\section{Gross Lesions}

Gross lesions in all dead calves of group-I varied from mild to clear cut haemorrhages along with congestion and emphysema in lungs in both the endotoxemic buffalo calves, besides congestion odema and dilation and haemorrhages on mucosal surface of intestines as well as in mediastinal lymph nodes, haemorrhages in the gall bladder mucosa and reddish discolouration of cortex of kidneys. The gross lesions, although non-specific, but were suggestive of toxemia, enteropathy and pulmonary failure accompanying endotoxic shock. Gross lesions in group II [13] were broadly similar to those in group I, except for epicardial and sub-endocardial haemorrhages in three endotoxemic buffalo calves and mild catarrhal enteritis in two animals. Epicardial and sub-endocardial haemorrhages were suggestive of either hypoxia or septicaemia or toxaemia or massive respiratory distress. Gross pathological changes in group III were similar to those seen in earlier groups, except for haemorrhages on mucosal surface of intestines as well as in mediastinal lymph node in one buffalo calf [19].

\section{Histopathology}

Histopatholgically, the lesions were more specific and the common findings in all the animals were congestion, haemorrhages and emphysema in lungs (Figure 1), necrotic enteritis with mononuclear cell infilteration, congestion and lower nephron nephrosis in kidneys, mild sinusoidal congestion and hepatocellular necrosis in liver. Fibrinous emboli in the microvasculature of lungs were also noticed in one buffalo calf. (Figure 2) Nagaraja et al. (1979) [27] also observed fibrin thrombi in arterioles and capillaries of lungs in endotoxemic calves. In another buffalo calf, marked superficial segmental necrosis of villi (Figure 3) was observed.

Singh et al. (1996) [28] observed atelactasis, congestion, haemorrhages and emphysema in lungs, edema in intestinal mucosa along with extensive coagulative necrosis of epithelial cells of villi, diffuse coagulative necrosis of convoluted tubules of kidney and congestion, haemorrhages with fatty degenera- 
tion and coagulative necrosis in liver. Sokkar et al. (2003) [29] also reported edema, congestion and haemorrhages in lungs, nephritic changes in kidney, areas of coagulative necrosis of the hepatocytes and necrosis of the intestinal villi with infiltration of polymorphs.

In one of the endotoxemic buffalo calf degenerative changes of cardiac myocytes along with mononuclear cell infiltration in perivascular region of the myocardium were also noticed, which hinted at cardiomyopathy. Hackel et al. (1974) [30] reported occurrence of myocytic necrosis and haemorrhage in the sub-endocardial region of myocardium in endotoxaemia. Singh et al. (1996) [28] and Nagaraja (1979) [27] also reported epicardial and sub-endocardial haemorrhages in endotoxemic calves. In another buffalo calf, congestion, haemorrhages and mild edema in the cerebrum (Figure 4) and in gall bladder haemorrhages along with sloughing of mucosa were also recorded. Nagaraja (1979) [27] and Sokkar (2003) [29] also reported numerous haemorrhages and edema in cerebrum of endotoxemic calves and rams respectively.

The major histopathological changes in group II were almost similar to those seen in group I, except for more prominent bronchio-interstitial changes in lungs which included mild interstitial pneumonia, sloughing of bronchiolar mucosa, haemorrhages, congestion and marked emphysema in some bronchioles, bacterial colonies were also observed in a few bronchioles which were surrounded by neutrophils. Over all the lungs appeared to be shock lung in such cases. Apart from these changes hyaline membrane formation was also noticed in the alveoli in two endotoxemic buffalo calves. Epicardial, sub-endocardial and myocardial haemorrhages noticed grossly were also prominent histopathologically. In one animal, there was degeneration and necrosis of cells of the zona fasciculata of adrenal glands (possibly related to stress, hyperproduction of corticosteroids and thereby exhaustion of cells in this zone [13].

Histopathologically changes in group III were similar to those in groups I and II.

One of the salient finding in all the groups was the presence of wide spread thrombi/emboli in lungs possibly indicating disseminated intravascular coagulopathy (DIC).

Wide spread changes of congestion, haemorrhages, degeneration and necrosis in most of the organs particularly those in lungs and heart as seen grossly and histopathologically indicated vascular damage and hypoxia related to endotoxemia.

\section{CONCLUSIONS}

A perusal of clinical signs, clinical chemistry and pathological lesions in dead calves indicated that there was a multi-organ damage and pathologies induced by entotoxic shock, which were critical for maintenance of life processes. If the damage becomes irreparable, the animal may die. However, constituting timely therapeutic regimens consisting of hypertonic saline solution, Flunixin meglumine and whole blood infusion as used in group-III of the present investigation could counter or reverse some of the deleterious effects of endotoxins and thereby save the precious life of the animals.

\section{CONFLICTS OF INTEREST}

The authors declare no conflicts of interest regarding the publication of this paper.

\section{REFERENCES}

1. Vincent, J.L. and Backer, D.D. (2001) Patho-Physiology of Septic Shock. Advances in Sepsis, 1, 87-92.

2. Hodgson, J.C. (2006) Endotoxin and Mammalian Host Responses during Experimental Disease. Journal of Comparative Pathology, 135, 157-175. https://doi.org/10.1016/j.jcpa.2006.09.001

3. Ng, S.W., Zhang, H., Hedge, A. and Bhatia, M. (2008) Role of Preprotachykinin-A Gene Products on Multiple Organ Injury in LPS-Induced Endotoxemia. Journal of Leukocyte Biology, 83, 288-295. https://doi.org/10.1189/jlb.0807575

4. Hardie, E.M. and Krusse-Elliott, K. (2008) Endotoxic Shock Part II: A Review of Treatment. Journal of Internal Medicine, 4, 306-314. 
5. Moore, J.N. and Barton, M.H. (2003) Treatment of Endotoxemia. Veterinary Clinics of North America: Equine Practice, 19, 681-695. https://doi.org/10.1016/j.cveq.2003.08.006

6. Thomas, J.S. (2000) Schalm's Veterinary Hematology. Chapter $13^{\text {th }}$, 5th Edition, Lippincott Williams and Wilkins Inc., 809.

7. Snecdecor, G.W. and Cochran, W.G. (1976) Statistical Methods. Iowa State College Press, Ames.

8. Sobti, V.K., Mirakhur, K.K., Krishnamurthy, D. and Nigam, J.M. (1981) Ringers Lactate and Homologous Blood Transfusion in Hemorrhagic Shock in Buffalo Calves. Indian Journal of Experimental Biology, 19, 371-374.

9. Singh, D.V., Singh, R.V. and Sodhi, S.P.S. (2004) Blood Biochemical Parameters during Bovine Endotoxemia and After I/V Infusion of Hypertonic Saline Solution and Plasmix-D-40. Indian Journal of Animal Sciences, 77, 438-441.

10. Kumar (1989) Hormonal and Biochemical Profile during Development and Reproductive Stages in Buffalo Calves. MVSc Thesis, Punjab Agricultural University, Ludhiana.

11. Jean, C.D., constable, P.D. and Yorchuk, K. (1993) The Clinical Use of Hypertonic Saline in Food Animals with Haemorrhagic and Endotoxic Shock. Agriculture Practice, 14, 6-11.

12. Zafar, M.A., Hussain, M.H., Muhammad, G. and Saqib, M. (2004) Potential Use of Hypertonic Saline Solution (7-7.5\% NaCl) Resuscitation in Hypovolemic and Endotoxic Shock. International Journal of Agriculture and Biology, 6, 926-930.

13. Nabi, I., Singh, D.V. and Sood, N.K. (2018) Patho-Physiology of Endotoxemic Buffalo Calves before and after I/V Infusion of Hypertonic Saline, Dextran-40 and Flunixin Meglumine. International Journal of Current Medical and Pharmaceutical Research (IJCMPR), 4, 3062-3067.

14. Singh, D.V. (2000) Physiological and Pharmacological Studies on Bovine Endotoxic Shock and Its Treatment. PhD Thesis, Punjab Agricultural University, Ludhiana.

15. Kaneko, J.J., Harvey, J.W. and Bruss, M.L. (1997) Clinical Biochemistry of Domestic Animals. $5^{\text {th }}$ Edition, Academic Press, New York, 126-134, 622, 893.

16. Ghuman, G.S. and Singh, D.V. (2009) Biochemical Profiles during Endotoxic Shock and after Hypertonic Saline Solution, Dexamethasone and Flunixin Meglumine Administration in Buffalo Calves. Toxicology International, 16, 73-76.

17. Deldar, A., Naylor, J.M. and Broom, J.C. (1984) Effect of E. coli Endotoxin on Leukocytes, Platelets Count, Fibrinogen Concentration in Colostrum Fed and Colostrum Deficient Neonatal Calves. American Journal of Veterinary Research, 45, 670-676.

18. Wycoff, H.D. (1970) Production of Fibrinogen Following the Endotoxin Injection. Proceedings of Experimental Biological Medicine, 133, 940-943. https://doi.org/10.3181/00379727-133-34599

19. Nabi, I., Singh, D. and Sood, N.K. (2013) Physiopathology Induced Endotoxaemia in Bovine and Its Treatment Regimen. Journal of Biomedical Science and Engineering, 6, 1077-1084.

https://doi.org/10.4236/jbise.2013.611135

20. Celly, C.S. and Prasad, B. (1987) Changes in Plasma, Cerebrospinal Fluid, Urinary and Salivary Electrolytes during Experimental Septic Shock in Calves. Indian Journal of Experimental Biology, 25, 73-74.

21. Singh, D.V., Sodhi, S.P.S. and Singh, R. (1994) Effect of Shock in Macro and Microelements Status in Cow and Buffalo Calves. Indian Veterinary Medical Journal, 18, 142-148.

22. Radostits, O.M., Gay, C.G., Blood, D.C. and Hinchcliff, K.W. (2000) Textbook of Diseases of Cattle, Sheep, Pigs, Goats and Horses. $9^{\text {th }}$ Edition, Chapter II, IX and Appendix, WB Saunders Company Ltd., 41-47, 410, 1820.

23. Singh, D.V. (1990) Effect of Circulatory Shock on the Cardiovascular System of Buffalo Calves. M.V.Sc. Disser- 
tation, Punjab Agricultural University, Ludhiana.

24. Constable, P.D., Schmall, M., Muir, W.W. and Hoffsis, G.F. (1991) Respiratory, Renal, Hematological and Serum Biochemical Effects of Hypertonic Saline Solution in Endotoxemic Calves. American Journal of Veterinary Research, 52, 990-998.

25. Singh, D.V. and Sodhi, S.P.S. (1992) Effect of Shock on Certain Biochemical Profiles of Blood in Calves. Indian Journal of Animal Sciences, 62, 1031-1036.

26. Singh, D.V., Singh, R.V. and Sodhi, S.P.S. (2007) Some Biochemical Profiles during Bovine Endotoxic (Lipopolysaccharide) Shock and after Treatment with Hypertonic Saline Solution. Indian Journal of Animal Sciences, 77, 438-441.

27. Nagaraja, T.G., Bartley, E.E, Anthony, H.D., Leipold, H.W. and Fina, L.R. (1979) Endotoxin Shock in Calves from Intravenous Injection of Rumen Bacterial Endotoxin. Journal of Animal Sciences, 49, 567-582. https://doi.org/10.2527/jas1979.492567x

28. Singh, D.V., Sodhi, S.P.S., Brar, A.P.S. and Grewal, J.S. (1996) Certain Pathological Profiles of Endotoxic Shock in Buffalo Calves. Buffalo Journal, 19, 283-288.

29. Sokkar, S.M., Darwiesh, G. and Madbooly, A. (2003) Study of the Pathological Effects of Escherichia coli Endotoxin in Rams. Journal of Veterinary Medicine, 50, 226-230. https://doi.org/10.1046/j.1439-0450.2003.00651.x

30. Hackel, D.B., Ratliff, N.B. and Mikat, E. (1974) The Heart in Shock: Brief Review. Circulation Research, 35, 805-811. https://doi.org/10.1161/01.RES.35.6.805 
GROUP-I

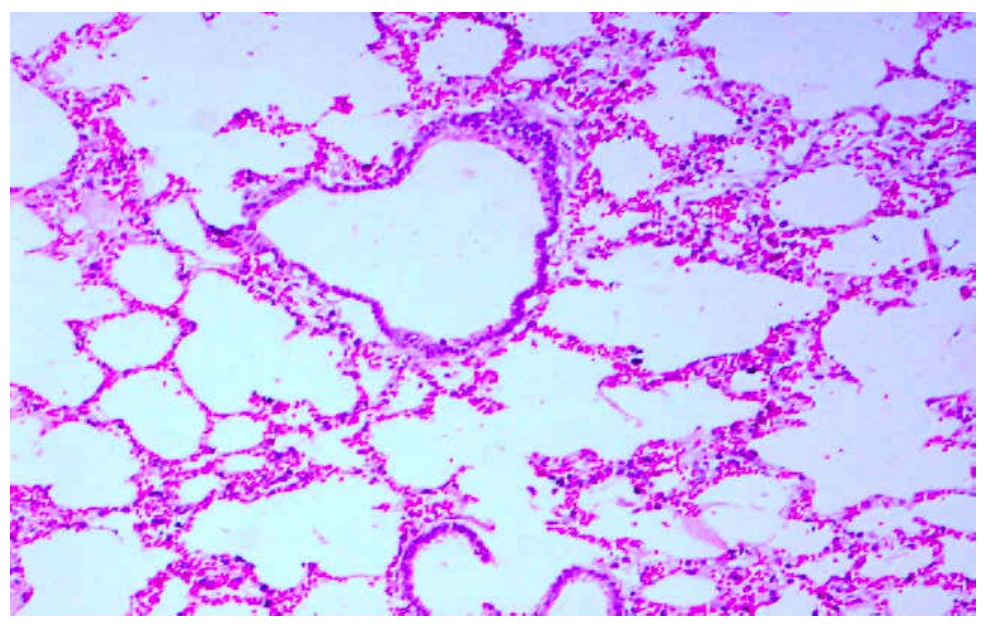

Figure A1. Lung-Marked congestion and emphysema (H. E.X150).

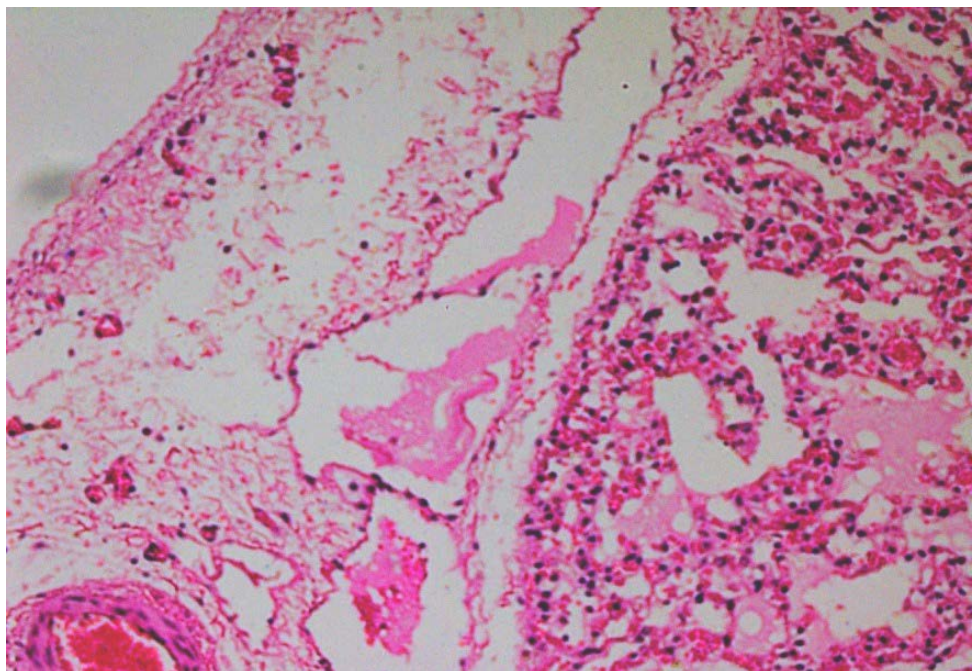

Figure A2. Lung-Congestion and Fibrinous emboli in vessel (H. E.X75).

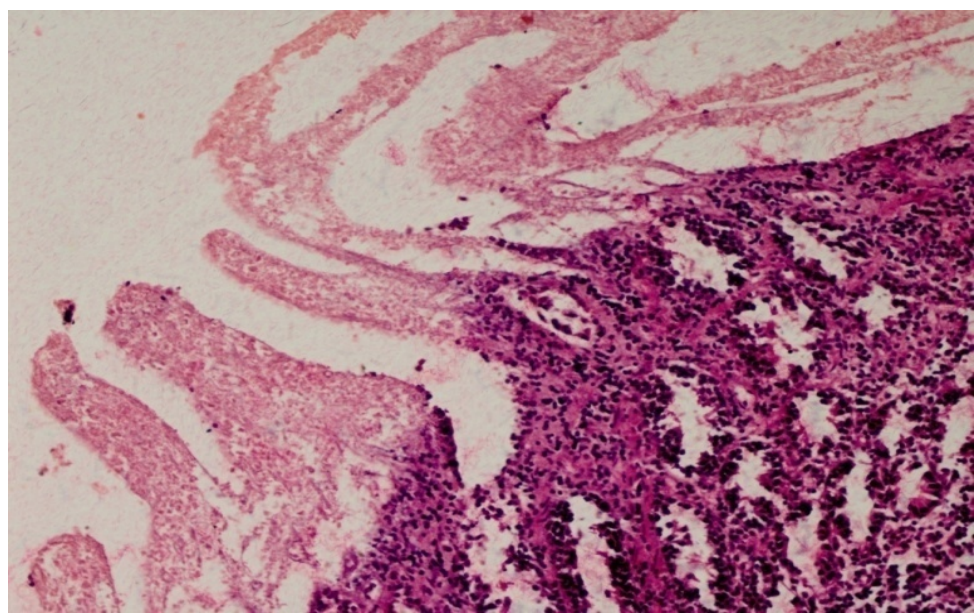

Figure A3. Intestine-Marked superficial segmental necrosis of villi (H. E.X150). 


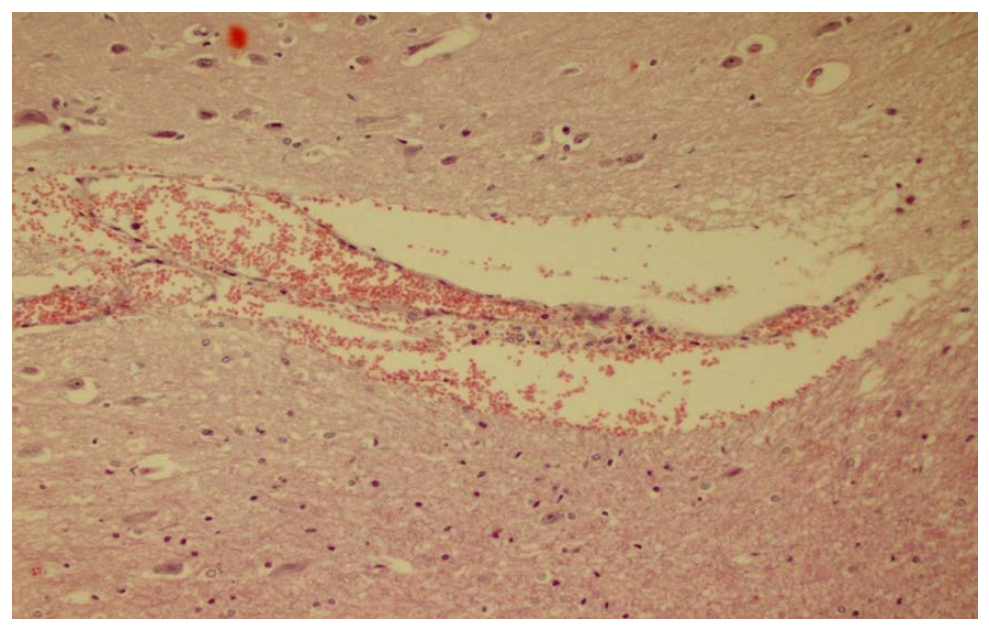

Figure A4. Cerebrum-Haemorrhages (H. E.X150). 